\title{
Energy Conversion of Circulating Water_—A Novel Idea on Water Loop Heat Pump System
}

\author{
Qi-Dong YU \\ School of Environmental Science and Engineering, Tianjin University, Tianjin 300072, China \\ E-mail: stevenyu78@sina.com \\ *Corresponding author: Qi-Dong YU
}

Keywords: Water loop heat pump, Circulating water, Auxiliary heat source, Office building

\begin{abstract}
To improve the research on water loop heat pump (WLHP) system, a technology chain composed of building, circulating water and units was used to build an idea of energy conversion and it states that circulating water can replace building load to solve the reverse energy of units to water loop. Based on the idea, the energy equations of circulating water and capacity modeling of auxiliary heat source are built and its capacity size is below $80 \%$ of design load for all types of building. An office building was tested to analyze the effect of auxiliary power on unit and system and the results show that a distorted point occurs at load rate of $80 \%$ and its energy consumption accounts for about $10 \%$ of the total, in addition, the capacity with $55 \%$ of design load is the most reasonable project and its energy-saving rates are $14.79 \%$ and $3.28 \%$ compared with others.
\end{abstract}

\section{Introduction}

Nowadays, the research on energy recovery system [1, 2] is a hot issue due to energy crisis and environmental concerns. As an important energy-saving device, the heat pump $[3,4]$ can recover waste heat to provide cooling and heating for a building, so its research has become the frontier of engineering science. At present, the water-loop heat pump (WLHP) [5, 6] has been widely used in many countries and it uses a closed loop composed of small water-air heat exchangers to recover waste heat from a building to make up for heat loss. The circulating water simultaneously provides heating and cooling for different areas of the building and its temperature is $16 \sim 32^{\circ} \mathrm{C}$ based on the previous investigation [7]. Note that when the water temperature reaches the lower limit of the range an auxiliary heat source is started to heat circulating water, similarly, a cooling tower is operated to remove waste heat at the upper limit, and its schematic diagram is shown in Fig. 1.

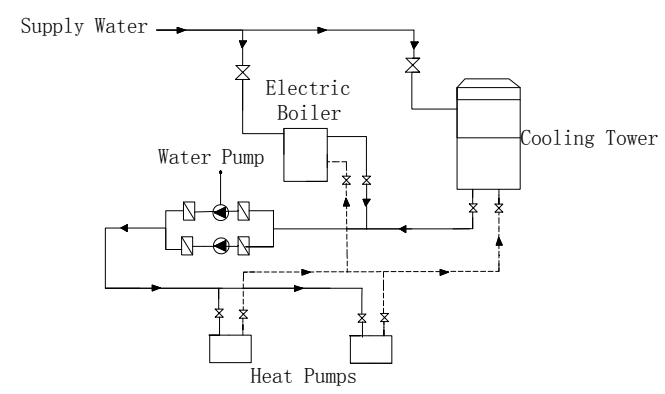

Fig.1 Schematic diagram of WLHP system

So, its research should concentrate on energy-saving rate and application area. In China, Ma [8] proposed a static method of primary energy to discuss its operation condition but the method had a certain limitation due to a combined effect of heating and cooling on coefficient K. Yu [9] built a method of energy gap to solve this problem and determined its energy-saving range. As far as application conditions were concerned, Lian [10] suggested its application area in China and combined with a case, Chen [11] investigated system operation in residential building. In addition, 
Shui [12] analyzed the effect of water temperature on compressor and cooling tower and $\mathrm{Yu}$ [13] revealed the relation between load rate and energy efficiency, which provided some important clues for the related research. In this paper, an idea of energy conversion is proposed to solve the reverse energy caused by units and determine the capacity model of auxiliary power. In addition, an office building also is test to analyze the effect of auxiliary power on unit and system and these conclusions provide a certain reference for further research.

\section{Modeling}

\section{Research Idea}

In WLHP system, the units provide cooling or heating for different areas of a building to reflect the energy effect caused by several factors, which rejects and extracts heat to and from a water loop to produce water temperature fluctuation. As the energy carrier the circulating water forms a secondary effect to change the COP of unit. So, the operation of WLHP system forms a technology chain of energy transfer and its structure is described in Fig. 2.

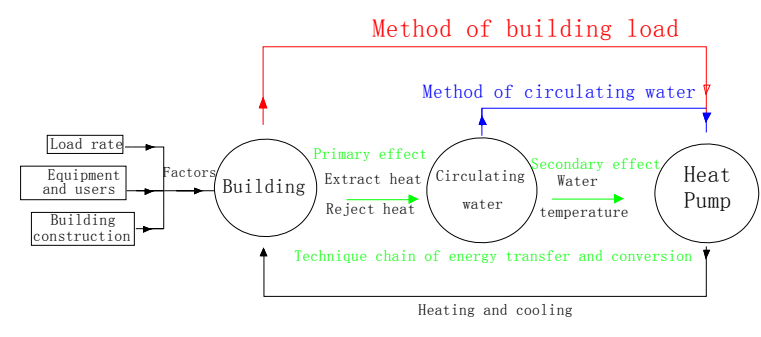

Fig.2 Structure chart of technology chain

In Fig. 2, we can obtain a same conclusion in the research process whether using circulating water or building load and some advantages also are seen if the circulating water replaces building load. First, the accuracy and applicability of method is improved due to cut research link. Second, the different effects are considered as a single function on circulating water. Third, the reverse energy caused by units is converted into the energy change of circulating water. So, we can build a technology chain composed of building, circulating water and units in WLHP system and the circulating water can replace building load to convert the reverse energy into the energy change of circulating water.

\section{Equations of Circulating Water}

WLHP system usually is used in the buildings with inner-outer zones but some units operate the cooling mode in winter, so, we introduce a concept of heating coefficient at design condition to evaluate the process and its definition is written in Eq. 1.

$$
K_{d}=\frac{Q_{d h}}{Q_{d h}+Q_{d c}}=\frac{Q_{d h}}{Q_{t}}
$$

Where, $K_{d}, Q_{d h}, Q_{d c}$ and $Q_{t}$ are the heating coefficient, heating load, cooling load and total load, respectively. Eq. 1 shows that $K_{d}$ is in the range of $0 \sim 1$ and can be determined for a specific case. In cooling mode, the units reject heat of $Q_{d c}\left(1+\frac{1}{\varepsilon}\right)$ to a water loop, which is considered as a stored energy for circulating water; similarly, they extract heat of $Q_{d h}\left(1-\frac{1}{\mu}\right)$ from the loop in heating mode to form a rejected energy. So, the energy equation at design condition is written as follows. 


$$
\Delta q_{d}=Q_{d h}\left(1-\frac{1}{\mu}\right)-Q_{d c}\left(1+\frac{1}{\varepsilon}\right)
$$

Where, $\Delta q_{d}$ is the energy change at design condition and $\varepsilon$ and $\mu$ are the average COP and thermal coefficient of heat pump. By introducing Eq. 1 and corresponding parameters into Eq. 2 the equation is rewritten as follows.

$$
\Delta q_{d}=Q_{t}\left(2.014 K_{d}-1.223\right)
$$

Heating load plays a dynamic role with building load when the WLHP system is operated at non-design conditions but the cooling load is constant in the process. So, we use the heating load at design condition to build the energy equation at non-design conditions. Based on the technology chain, we find that load rate possesses the double characteristics of quality and quantity and quality reflects different requirements for cooling or heating but quantity is its size, in addition, the energy with different attributes is produced to change the energy of circulating water with building load. So, the energy change of circulating water yields to Eq. 4.

$$
\Delta q_{n d}=\eta \Delta q_{d}-E_{c}
$$

Where, $\Delta q_{n d}, \eta$ and $E_{c}$ are the energy change at non-design conditions, load rate and reverse energy caused by units. We use a back-stepping method to derive the load change and determine $E_{c}$ in Eq. 4. The energy change of circulating water is $\Delta q_{d}(1-\eta)$ with building load and the process converts a part of heating load into equal cooling load and its change and conversion energy are $\frac{1-\eta}{1-\frac{1}{\mu}} \Delta q_{d}$ and $(1-\eta) \frac{1+\frac{1}{\varepsilon}}{1-\frac{1}{\mu}} \Delta q_{d}$. So, the equation at non-design conditions can be built by using Eq. 4.

$$
\Delta q_{n d}=\eta \Delta q_{d}-(1-\eta) \frac{1+\frac{1}{\varepsilon}}{1-\frac{1}{\mu}} \Delta q_{d}
$$

We define a coefficient of energy conversion $(\varphi)$ to evaluate the process and it is written in Eq. 6 .

$$
\varphi=\frac{1+\frac{1}{\varepsilon}}{1-\frac{1}{\mu}}
$$

Where, $\varphi$ is the coefficient of energy conversion and here 1.55 is taken by $\varepsilon$ and $\mu$. Based on a comparison between $Q_{c}\left(1+\frac{1}{\varepsilon}\right)$ and $Q_{h}\left(1-\frac{1}{\mu}\right)$, we find its several technical characteristics. First, the intensity of energy is greater in cooling than heating mode for a same load size. Second, the reverse energy is in a enhance process when the units are converted into heating mode with load rate increasing. So, Eq. 5 is rearranged by using Eq. 6.

$$
\Delta q_{n d}=\eta \Delta q_{d}-\varphi(1-\eta) \Delta q_{d}
$$

Based on Eq. 3 and corresponding parameters the energy equation at non-design conditions finally yields to Eq. 8 .

$$
\Delta q_{n d}=Q_{t}\left(2.014 K_{d}-1.223\right)(2.55 \eta-1.55)
$$


As noted above, we summarize the energy equations of circulating water as follows.

$$
\Delta q=\left\{\begin{array}{cc}
Q_{t}\left(2.014 K_{d}-1.223\right), & \eta=100 \% \\
Q_{t}\left(2.014 K_{d}-1.223\right)(2.55 \eta-1.55), \eta \in(0,100 \%)
\end{array}\right.
$$

Eq.9 tells us some new clues. First, the energy change of circulating water is a single function on load rate. Second, the equation has an extreme point to change its original law due to the load range of $0 \% \sim 100 \%$ and its range is relevant with the meteorological parameters and building type.

2.3 Capacity modeling

Auxiliary power is used to make up for heat loss in winter, so its size is determined according to the energy change of circulating water. When the size is selected in accordance with the energy change at design condition, the COP of units is higher but the function of heat pump can't fully be used because the energy extracted from circulating water is not as high as the heat provided by auxiliary power, whereas, the energy consumption of units obviously increases, which reveals an energy balance between units and auxiliary power. Based on this, when the WLHP system is used in a building without inner-outer zones we can determine $K_{d}$ and its capacity as follows.

$$
Q_{\text {without }}=0.791 Q_{t}, K_{d}=1
$$

Where, $Q_{\text {without }}$ is the capacity in the building without inner-outer zones. According to the literature [14], $K_{d}$ is in the range of 0.8 0.85 when WLHP system is used in the building with inner-outer zones in northern China and its capacity is written as follows.

$$
Q_{\text {with }}=\left\{\begin{array}{c}
0.388 Q_{t}(2.55 \eta-1.55), K_{d}=0.8 \\
0.489 Q_{t}(2.55 \eta-1.55), K_{d}=0.85
\end{array}\right.
$$

Where, $Q_{\text {with }}$ is the capacity in the building with inner-outer zones. We define a capacity coefficient $(g)$ to study the change of auxiliary power with load rate as follows.

$$
g=\frac{Q_{w i t h}}{Q_{t}}=\left\{\begin{array}{cl}
0.99 \eta-0.6, & K_{d}=0.8 \\
1.25 \eta-0.76, & K_{d}=0.85
\end{array}\right.
$$

The changes of capacity size with load rate are described in Fig. 3.

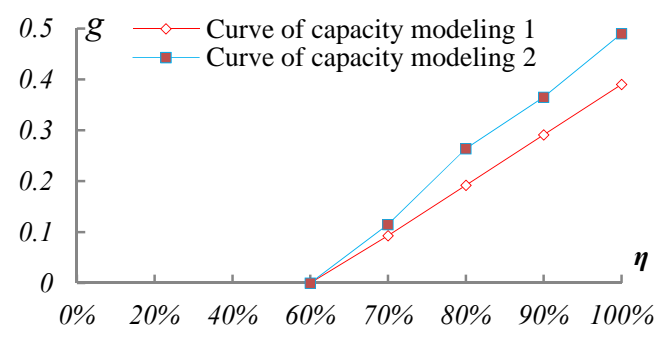

Fig.3 Change curves of capacity size with load rate changing

Fig. 3 tells us the following conclusions. First, their changes yield to an approximate linear law with load rate increasing and load rate plays a key role in the process. Second, the WLHP system operates efficiently without external energy at load rate of $60 \%$ and the load rate is a balance point. Third, the range of capacity size is below $50 \%$ of design load for the buildings. 


\section{Types of Buildings}

As noted above, the capacity modeling of auxiliary power is generalized as follows.

$$
\left\{\begin{array}{c}
Q_{1}<80 \% Q_{t} \\
50 \% Q_{t}<Q_{2}<Q_{1} \\
Q_{3}<50 \% Q_{t}
\end{array}\right.
$$

Where, $Q_{1}, Q_{2}$, and $Q_{3}$ are its capacity sizes in the building without inner-outer zones, third type of building and with inner-outer zones. Eq.13 shows that the WLHP system can't be used if the capacity size is $Q_{1}$ but it can achieve a higher energy-saving rate when the size is $Q_{3}$, which causes an issue that is whether the WLHP system can be used in the third type of building if the size is $Q_{2}$.

\section{Test and Discussion}

\section{Project}

Office building has been widely used in China but high consumption and intermittency are its important characteristic, in addition, the heat gain also makes a great difference in different orientations, which leads to the different requirements for heating and cooling, so, we select a two-story office building with area of $1000 \mathrm{~m}^{2}$ to validate the third type of building and its indoor design temperatures are $27^{\circ} \mathrm{C}$ in summer and $21^{\circ} \mathrm{C}$ in winter and cooling and heating loads are $108 \mathrm{~kW}$ and $72 \mathrm{~kW}$ respectively. The 24 sets of SHR series unitary units are installed in the building and the heating capacity per unit is $120 \mathrm{~kW}$ and $110 \mathrm{~kW}$ for cooling capacity and corresponding input power is $26 \mathrm{~kW}$ and $24 \mathrm{~kW}$. The electric boilers are used as the auxiliary power in winter and their sizes are selected according to $50 \%, 55 \%$ and $60 \%$ of design load.

\subsection{Test}

Based on the change of outdoor temperature system load is divided into five sections of $100 \%$ $80 \%, 80 \% \sim 60 \%, 60 \% \sim 40 \%, 40 \% \sim 20 \%$, and $20 \% \sim 0 \%$ and five typical load rates of $100 \%$, $80 \%, 60 \%, 40 \%, 20 \%$ are used to test the system. Their consumptions are shown in Table 1-3.

Table 1 energy consumption in scheme 1

\begin{tabular}{llllcll}
\hline $\begin{array}{l}\text { Load } \\
\text { rate }\end{array}$ & $\begin{array}{l}\text { Unit } \\
\text { power(kW) }\end{array}$ & $\begin{array}{l}\text { Pump } \\
\text { power(kW) }\end{array}$ & $\begin{array}{l}\text { Auxiliary } \\
\text { power }(\mathrm{kW})\end{array}$ & $\begin{array}{l}\text { System } \\
\text { power }(\mathrm{kW})\end{array}$ & Time(h) & $\begin{array}{l}\text { Energy } \\
\text { consumption(kWh) }\end{array}$ \\
\hline $100 \%$ & 12.08 & 2.0 & 36.00 & 50.08 & 75 & 3756 \\
$80 \%$ & 4.23 & 2.0 & 28.80 & 35.03 & 375 & 13136 \\
$60 \%$ & 3.22 & 2.0 & 21.60 & 26.82 & 600 & 16092 \\
$40 \%$ & 2.27 & 2.0 & 14.40 & 18.67 & 300 & 5601 \\
$20 \%$ & 1.18 & 2.0 & 7.20 & 10.38 & 150 & 1557 \\
\hline
\end{tabular}

Table2 energy consumption in scheme 2

\begin{tabular}{llccccc}
\hline $\begin{array}{l}\text { Load } \\
\text { rate }\end{array}$ & $\begin{array}{l}\text { Unit } \\
\text { power(kW) }\end{array}$ & $\begin{array}{l}\text { Pump } \\
\text { power(kW) }\end{array}$ & $\begin{array}{l}\text { Auxiliary } \\
\text { power }(\mathrm{kW})\end{array}$ & $\begin{array}{l}\text { System } \\
\text { power }(\mathrm{kW})\end{array}$ & Time(h) & $\begin{array}{l}\text { Energy } \\
\text { consumption(kWh) }\end{array}$ \\
\hline $100 \%$ & 8.78 & 2.0 & 39.60 & 50.38 & 75 & 3779 \\
$80 \%$ & 5.21 & 2.0 & 22.16 & 29.37 & 375 & 11014 \\
$60 \%$ & 4.04 & 2.0 & 17.11 & 23.15 & 600 & 13890 \\
$40 \%$ & 2.71 & 2.0 & 11.69 & 16.40 & 300 & 4920 \\
$20 \%$ & 1.33 & 2.0 & 5.78 & 9.11 & 150 & 1367 \\
\hline
\end{tabular}


Table 3 energy consumption in scheme 3

\begin{tabular}{lcccccc}
\hline $\begin{array}{l}\text { Load } \\
\text { rate }\end{array}$ & $\begin{array}{l}\text { Unit } \\
\text { power }(\mathrm{kW})\end{array}$ & $\begin{array}{l}\text { Pump } \\
\text { power(kW) }\end{array}$ & $\begin{array}{l}\text { Auxiliary } \\
\text { power }(\mathrm{kW})\end{array}$ & $\begin{array}{l}\text { System } \\
\text { power }(\mathrm{kW})\end{array}$ & Time(h) & $\begin{array}{l}\text { Energy } \\
\text { consumption(kWh) }\end{array}$ \\
\hline $100 \%$ & 4.35 & 2.0 & 43.20 & 49.55 & 75 & 3716 \\
$80 \%$ & 5.03 & 2.0 & 24.12 & 31.15 & 375 & 11681 \\
$60 \%$ & 3.78 & 2.0 & 18.04 & 23.82 & 600 & 14292 \\
$40 \%$ & 2.52 & 2.0 & 12.16 & 16.68 & 300 & 5004 \\
$20 \%$ & 1.42 & 2.0 & 6.07 & 9.49 & 150 & 1424 \\
\hline
\end{tabular}

Discussion

We use design power as the base line to discuss the power change with load rate and the changes of unit power are drawn in Fig. 4. Fig. 4 shows that they yield to different nonlinear laws with load rate increasing and a distortion point occurs at load rate of $80 \%$ but the fluctuations produced by power change make a great difference and become more obvious at load rate of $20 \% \sim 80 \%$ with size increasing based on a reverse relation between the base line and capacity size. Note that they are drastically increased at load rate of $80 \% \sim 100 \%$ for scheme 1 and 2 due to less COP and more consumption of auxiliary power but a reverse trend occurs in project 3 because a part of energy is replaced by heat provided by auxiliary power, which reduces the power output of units at the cost of consuming auxiliary power. So, the size of auxiliary power is another impact factor in addition to load rate and their changes are described in Fig. 5.

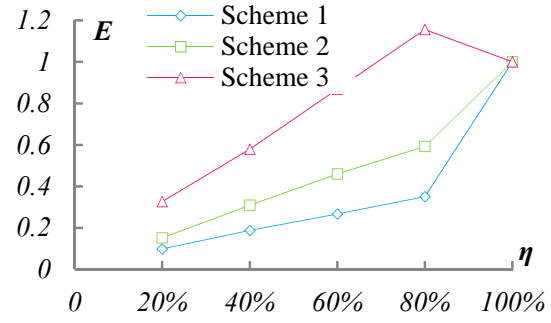

Fig.4 Change chart of unit power in three schemes Fig.5 Change chart of auxiliary power in three schemes

In Fig 5, we find that the change of auxiliary power shows a linear characteristic in scheme 1 but it is converted into a similar nonlinear law and inflection point occurs at load rate of $80 \%$ in other schemes. In scheme 1, the heat provided by auxiliary power is determined based on several typical condition points due to smaller capacity size but the scheme continually is decreased with capacity size increasing. With respect to a certain similarity in scheme 2 and 3 , we analyze that the heat supply generally is smaller than capacity size at partial load and the difference produced by different sizes will continually be enhanced with supply increasing and is shown at load rate of $60 \% \sim 80 \%$. So, we conclude that the energy balance between auxiliary power and units can suppress the power fluctuation produced by load change to improve overall operation and its actual impact on system power can be seen in Fig. 6. Fig. 6 shows that the changes of system power yield to the similar laws in three schemes and inflection point occurs at load rate of $80 \%$ but note that their fluctuations make a certain difference with load rate increasing, which validates the effect of a distortion point on system operation and states that the load change has a negative effect on energy-saving potential but the reasonable capacity size can decrease its impact. In order to further investigate the effect of running time on system operation, we draw the changes of energy consumption in three schemes and they are shown in Fig. 7. 


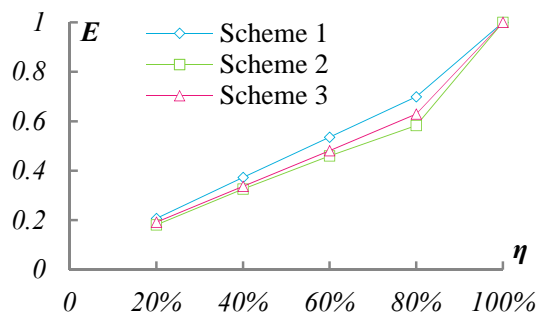

Fig.6 Change chart of system power in three schemes

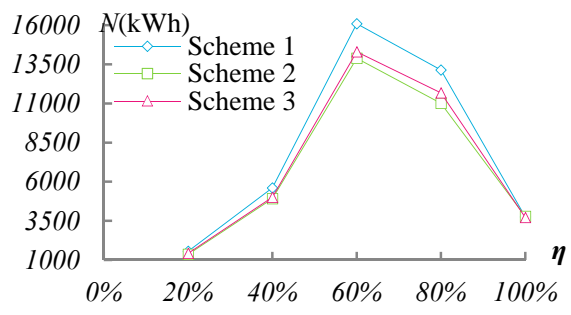

Fig.7 Change chart of energy consumption in three schemes

As shown in Fig. 7, the changes of energy consumption yield to a similar law for three schemes but we should notice the following several points. Firstly, the running time is more at load rate of $20 \% \sim 80 \%$ compared to others and its consumption plays a key role. Secondly, the difference of energy consumption in three schemes continually is enhanced with running time increasing. Thirdly, project 2 has a higher energy efficiency compared to others because it optimizes the energy balance between auxiliary power and units. So, the running time determines total consumption and energy-saving rate but also changes the effect of auxiliary power on energy consumption.

\section{Conclusions}

The paper uses a technology chain composed of building, circulating water and units to build an idea of energy conversion and it states that circulating water can replace building load to determine the reverse energy of units to water loop. Based on this idea, the energy equations of circulating water and capacity modeling of auxiliary power are built and its capacity size is below $80 \%$ of design load for all types of building. By testing an office building in Tianjin the results show that a distorted point occurs at load rate of $80 \%$ and its consumption accounts for about $10 \%$ of total, in addition, the scheme with $55 \%$ of design load is more reasonable and its energy-saving rates are $14.79 \%$ and $3.28 \%$ compared to others.

\section{References}

[1] Lucio Postrioti, Giorgio Baldinelli, Francesco Bianchi, et al. An experimental setup for the analysis of an energy recovery system from wastewater for heat pumps in civil buildings, Appl Therm Eng, 102(2016) 961-971.

[2] Jörgen Wallin, Joachim Claesson. Improving heat recovery using retrofitted heat pump in air handling unit with energy wheel, Appl Therm Eng, 62(2014) 823-829

[3] Zhaorui Zhao, Ziwen Xing, Feng Hou, et al. Theoretical and experimental investigation of a novel high temperature heat pump system for recovering heat from refrigeration system, Appl Therm Eng, 107(2016) 758-67.

[4] Chun-Lu Zhang, Han Yuan. New insight into regenerated air heat pump cycle, Energy, 91(2015) 226-234.

[5] J.A. Pietsch, Water-loop heat pump systems assessment, ASHRAE Trans, 96(1990) 1029-1038.

[6] Wang SK. Handbook of air conditioning and refrigeration, New York (NY): McGraw-Hill; 2001.

[7] LI Xin-guo. Thermal performance and energy saving effect of water-loop heat pump systems with geothermal, Energ Convers Manage, 39(1998) 295-301

[8] MA Zui-liang, CAO Yuan. Operation consumption static analysis on water-heat pump air conditioning system, J. Harbin Inst. Technol, 30(1997) 68 -74

[in Chinese] 
[9] Chang Ru, Yu Qi dong. Energy-saving analysis for water-loop heat pump system based on energy gap theory, J. Central South Univ, 45(2014)847-54

[in Chinese]

[10] Lian Zhi-wei, Seong-ryong Park, Qi He-nian. Analysis on energy consumption of water-loop heat pump system in China, Appl Therm Eng, 25(2005) 73-85

[11] Chao Chen, Sun Feng-ling, Feng Lei, et al. Underground water-source loop heat-pump air-conditioning system applied in a residential building in Beijing, Appl Energy, 82(2005) 331-344

[12] Yuan Shui, Michel Grabon. Optimizing energy consumption of a water-loop variable-speed heat pump system, Appl Therm Eng, 31(2011) 894-901

[13] Yu Qi-dong. Part Load Ratio on the Impact of Energy Consumption of Heat Pump System, Fluid Machinery, 40(2012)76-80 [in Chinese]

[14] Ma Zui-liang, Cao Yuan. The Evaluation of the WLHP used in China, Refrigation, 1997(61): 11-16 [in Chinese] 